O.G. Volkova, L.B. Zhornyak

\title{
INVESTIGATION OF HIGH-CURRENT INTERRUPTING CONTACTS WORKING SURFACES MECHANICAL INTERACTION NATURE
}

Introduction. The nature of the interaction of high-working surfaces of the electrical contact uniquely affects their performance. By the failure of the contacts in the main drive processes resulting from complex destructive factors affecting their performance. However, not all processes are studied in detail and give in modeling. The purpose of the paper is to show the possibility of using the method of holographic interferometry to estimate the plastic deformation in the zone of contact interaction. One of the significant factors affecting the work of the contact pair is the compressive force of the contact surfaces. Compression discontinuous contact is directly connected with the processes of elastic and plastic deformation of the contact material, which is particularly evident in the contact details of the powder or composite materials. The paper focuses on the plastic deformation of the surface layers of discontinuous contact in circuit, it is believed that it is directly related to the mechanism of conductivity of contacts. As shown, a significant effect on the deformation of the contact surfaces and renders the working environment, in particular transformer oil. Methodology. Assessing the impact of compression forces on the deformation of the contact surface was conducted experimentally using the method of holographic interferometry. Results. Experimental studies, which indicated that the compact and powder materials plastic deformation in and around the area microcontacts simplistically stated that requires experimental verification. A method for evaluating the state of stress, which affects the formation and destruction of the local contact spots. Practical value. Using the experimental method of determining the movement of the contact region allows you to optimize discontinuous contacts from composite and powder materials. References 7, tables 2, figures 4.

Key words: electrical contacts, contact surfaces, deformation of contact materials, method of holographic interferometry.

Характер взаимодействие рабочих поверхностей сильноточных электрических контактов однозначно влияют на их работоспособность. К отказу в работе контактов в основном приводят процессы, возникающие в результате комплекса факторов деструктивно влияющих на их работоспособность. При этом не все процессы подробно изучень и поддаются моделированию. Одним из существенных факторов, влияющцм на работу контактной пары, служит усилие сжсатия контактных поверхностей. Сжатие разрывных контактов напрямую связано с процессами упругой и пластической деформации контактных материалов, что особенно наглядно проявляются на контакт-деталях из порошковых или композиционных материалов. В статье основное внимание уделяется пластической деформации поверхностных слоев разрывных контактов в процессе замыкания, поскольку считается, что она напрямую связана с механизмом проводимостью контактов. Как показано, существенное влияние на деформацию контактных поверхностей оказывает и рабочая среда, в частности трансформаторное масло. Оценка влияния усилия сжсатия на деформацию контактной поверхности проводилась экспериментально с использованием метода голографической интерферометрии. Приведены результаты исследования, в которых указывалось, что для компактных и порошковых материалов пластическая деформация внутри и вокруг зоны микроконтактов указывается упроценно, что требует экспериментального уточнения. Библ. 7, табл. 2, рис. 4.

Ключевые слова: электрические контакты, контактные поверхности, деформация контактных материалов, метод голографической интерферометрии.

Introduction. The mechanism of the conduction of current through the contact is determined by the state of the contact surfaces and contacting conditions. It is known that the compressive force is one of the main factors shaping the nature of the contact interaction. Without sufficient compressive force the contact resistance increases, or conductivity of contacts is completely broken. The conductivity is proportional to the compression force, leading to the first elastic and then plastic deformation of the contact surfaces. Naturally, together with the change of compression force, the internal mechanical stress in the contact material changes. Distribution of plastic deformation of powder and composite materials is more complicated than for compact (cast) materials and assessment of the behavior of the surfaces contact-details made from these materials should be based on experimental observations, rather than simplified models.
The goal of the paper is to demonstrate the possibility of using the method of holographic interferometry to estimate the plastic deformation in the zone of contact interaction.

Modeling of contact surfaces interaction. Experimentally proved that a decrease in compression force in 2 times, transition resistance of contact-pieces depending on their size can be increased in 4 times or more. For high-current contacts there is an empirical relationship [1] showing that the contact resistance $R_{c}$ is mainly a function of the compression force, and the role of other factors, such as surface films is secondary and is taken into account by correction factors:

$$
R_{\mathrm{c}}=\frac{k \cdot\left(1+\frac{2}{3} \cdot \alpha \cdot T\right)}{\left(0,1 \cdot P_{c}\right)^{m}} .
$$

(C) O.G. Volkova, L.B. Zhornyak 
where $\alpha$ is the resistance temperature coefficient, $1 /{ }^{\circ} \mathrm{C} ; \mathrm{T}$ is the temperature of the contact's heating, ${ }^{\circ} \mathrm{C} ; P_{c}$ is the contacts compression force, $\mathrm{N} ; k, m$ are the coefficients taking into account contact materials and contacting nature.

The desire to find the general laws of the transition resistance of the compression force leads to the modeling of contact problems in the simplified model. For example, at the contact interaction simulation as a compression of two elastic spherical surfaces. According to the Hertz formula, the radius of the contact area of this model will be:

$$
r=0,9 \cdot \sqrt[3]{\frac{P_{c} r_{e f f}}{E}},
$$

where $P_{c}$ is the contacts compression force; $r_{\text {eff }}$ is the effective radius of curvature of the contact surfaces; $E$ is the contact materials modulus of elasticity [2].

In this case, the contact resistance can be expressed by the formula

$$
R_{c}=\frac{\varepsilon}{P_{c}^{1 / 3}} .
$$

In the range of compression force from 20 to $500 \mathrm{~N}$, which is typical for most of the switching devices, the value of the empirical coefficient $\varepsilon$ can be taken as follows: for copper $47 \cdot 10^{-6} \Omega \cdot \mathrm{kg}^{1 / 3}$; for brass $200 \cdot 10^{-6}$ $\Omega \cdot \mathrm{kg}^{1 / 3}$.

At the plastic nature of the contact interaction, when the radius of the area of collapse is given by equation

$$
r=\sqrt{\frac{P_{c}}{\pi \sigma_{c}}},
$$

where $\sigma_{c}$ is the collapse resistance of contact materials, the contact resistance of contact is assessed as [2]

$$
R_{c}=\frac{k}{P_{c}^{1 / 2}},
$$

where the coefficient коэффициент $k$ for some contact materials are presented in Table 1.

Table 1

Contact materials properties

\begin{tabular}{|c|c|}
\hline Contact materials & $\begin{array}{c}\text { Coefficient } k \text { for high-current contacts, } \\
\Omega \cdot \mathrm{kg}^{1 / 2}\end{array}$ \\
\hline Copper & $1.0 \cdot 10^{-4}$ \\
Silver & $0.5 \cdot 10^{-4}$ \\
Brass & $6.7 \cdot 10^{-4}$ \\
Steel & $7.6 \cdot 10^{-4}$ \\
\hline
\end{tabular}

The ratio between the applied load and the actual contact area can be represented as

$$
P_{c 1}=\zeta \cdot H \cdot A_{i},
$$

where $1 / 3 \leq \zeta \leq 1$ is the coefficient taking into account the elastic component of the deformation of the contact surfaces; $H$ is the hardness of the contact material taking into account the temperature; $A_{i}$ is the actual contact area.

Guided by similar models, contact problem is solved by using computer by numerical methods simultaneously with evaluation zones of contact interaction with the elastic and plastic deformation.

There are software packages that allow to simulate these processes and to ensure their control. These requirements largely correspond to software packages for finite element analysis (e.g. ANSYS), which have recently been widely used in the calculations of various mechanical structures.

A common approach to solving the problems of contact interaction of solid surfaces is reduced to a phased implementation of the following basic steps of calculation [3]:

1. Creation of solid objects that represent the geometry of the switching contacts, and their meshing.

2. The determination of a contact pair.

3. Appointment of the target and contact surfaces, elements of which are interconnected by physical constants and allow to take into account the kinematics of the deformation of the contact.

4. Determination of the key features of elements and actual constants of contact surfaces.

5. Determination of motion of a rigid contact surface.

6. Specification of the necessary boundary conditions.

7. Setting options of force loading and the problem solution.

8. The solution of the contact problem.

9. Analysis of the results.

As an example a 2D picture of the contact interaction of the main contacts of the contactor of the onload tap-changing transformer KHOA 110/1000 may be considered. Fig. 1 shows elements of the contact pair in the form of closed elastic-plastic bodies covered with the finite element (FE) mesh.
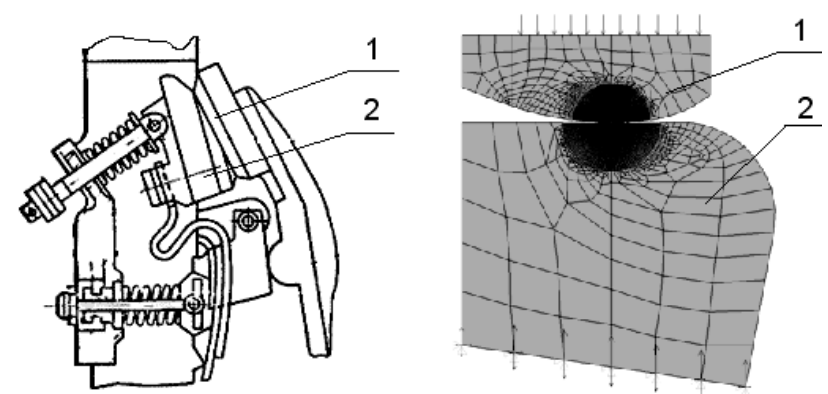

Fig. 1. An example of the use of the finite element analysis to study the interaction of pairs of contact: 1 - movable contact; 2 - fixed contact

The introduction of such techniques, provided the stability of the mechanical properties of the contact surfaces, allows to solve contact problems quickly and with greater accuracy. However, when assessing the effect of the compression force it is necessary to take into account the mechanical properties of contact materials (at operating temperatures), configuration and microgeometry of contacting surfaces, as well as the mechanical and adhesive properties of surface films and others. Such a number of factors suggests that analytically 
it is impossible to establish a general pattern for the compression forces ensuring optimal operation of the contacts [4].

Experimental determination of the contact surface deformation. Simulation methods do not allow to adequately take into account the real nature of the interaction of the contact details for long term of use, due to the development of destructive processes on their surfaces. It is not only the shielding effect of surface films, the effect of which is well known [5], and the plastic deformation of the contact surfaces. The cause of this is the high value for the compressive force of the contact surfaces, electrothermal processes, and plasticizing effect of the environment, such as transformer oil.

In general, the deformation of the surface layer has a complex mechanism, because the plastic material of the contact can not only spread but also to penetrate into the body contact. Under the influence of the compressive force varies and the internal mechanical stress in the contact material. The force of compression is set to the maximum possible for a particular contact pair not only improves the conductivity, but also leads to deformation and destruction of the contact surfaces during operation, and hence reduces their efficiency.

Particularly, these processes are shown in the contact pairs of powder and composite materials. The widespread use of multi-component powder materials for discontinuous contacts in high-switching devices is a common practice. The work of these materials is of interest because of their specific behavior that requires more detailed study.

Multicomponent powders and composite materials generally have a sufficiently high strength, due to the presence of the frame structure. Consider this as an example of a contact material КМК-Б20, used for highcurrent contacts in the contactors of the on-load tapchanging transformer (Fig. 2).

Frame consisting of solid compounds based on W, $\mathrm{Ni}$ or $\mathrm{Ti}, \mathrm{Cr}, \mathrm{Zr}$ receives mechanical stress from the main compression force and displacement, which stabilizes the amount of strain in the material and contact surface. To improve the antifriction and ensure the hardness value of the contact pair in the material composition is administered as a solid lubricant of molybdenum disulfide, graphite and others. Plastic conductive base (copper) of powder material largely relieved by the application of compression force and the biasing force, and it is only the volume adjacent to the area of direct contact, experiencing stress.

Furthermore dissipation of mechanical energy due to the compression and friction of the contact surfaces when switching occurs and accumulation of residual stress at the sites of actual contact [6]. Because of the random shape and dimensions of irregularities, as well as their locations on the friction surface, the residual stresses are randomly distributed over the surface and over time. An important role is played and by the porosity of the structure. If in some areas in a given time is an accumulation of internal energy (elastic deformation), the other process may be reaching a maximum decay with the release of heat or the formation of fracture nucleus. The area of increased ductility generally coincides with the area of greatest stress, i.e. the central region touch pad. After multiple cycles of closure-opening contacts are prerequisites for the emergence of cracks, leading to the destruction of the working surfaces of the contact pair. Presence of stochastically arranged in the powder material porosity evident as fracture cracks and ductility in the contacting zone.

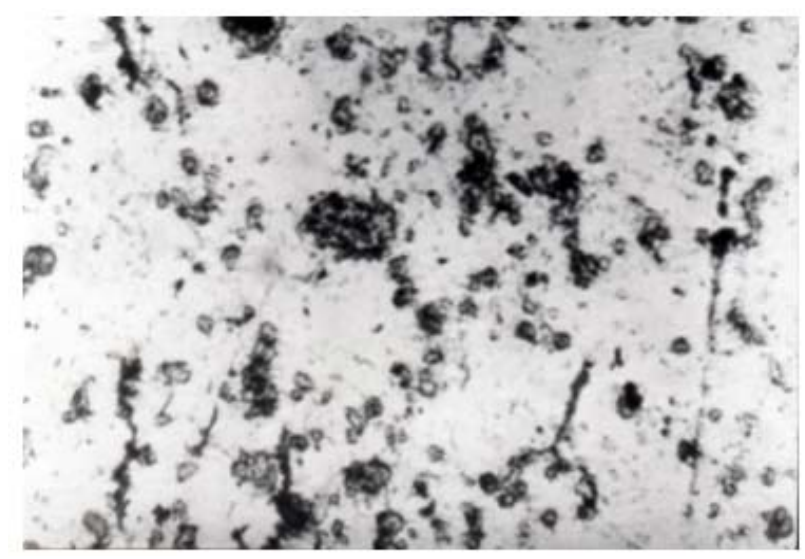

$a$

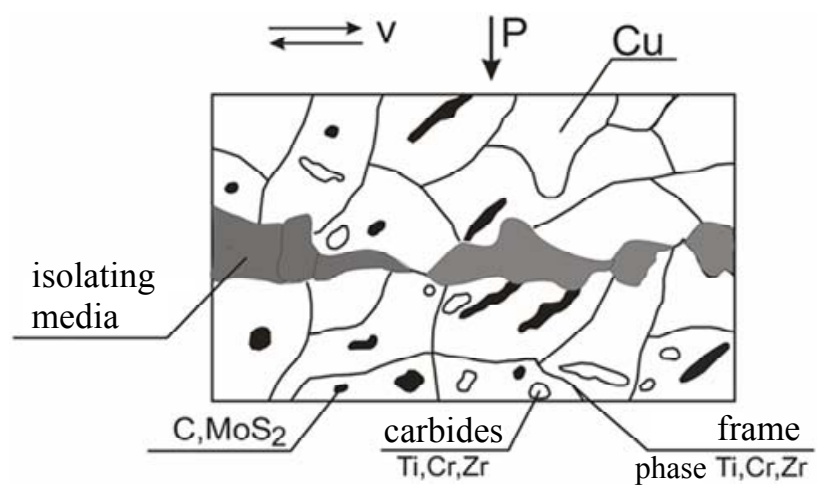

$b$

Fig. 2. The structure of the multi-component powder material $(a)$ and model of the contact surface $(b)$

Behavioral fluctuations of contact surfaces of the compact and powder materials, can be seen on the model of the contact pairs in the design of the on-load tapchanging transformer PHTA 35/320. For comparison, the moving contacts materials were chosen copper M1 and powder material КМК-Б20. The material of the fixed contact in both cases was brass ЛС 59-1.

In the experiment the method of investigation of contact interaction of solid bodies using holographic interferometry, which allows to record the displacement vector of points of the contact area by a double exposure of the subject of observation under a light source of coherent radiation is used. 
During the experiment, the contacts were fixed in the support prism with loading device and were the subject in a holographic pattern as shown in Fig. 3. The original survey was carried out on the contact plate in the unloaded condition. Subsequently a repeated exposure of contacts loaded compression forces $P, Q_{1}, Q_{2}$ on the same photographic plate.

If the thus obtained double-exposed hologram illuminate by a copy of the reference wave, then there is a holographic image of the contact pairs with superimposed grid of fringes. The strips are located on the subject, and on the adjoining area. Photocopies of such holograms are shown in Fig. 4.

Quantitative estimation of the deformation of the contact surface was carried out by monitoring the deflection of the interference fringes of the so-called zeroorder band. In this case, the zero-order interference fringe is defined as a single, it does not change its position when the double exposure. Visually, this is defined as the maximum bright band on the interferogram [7].

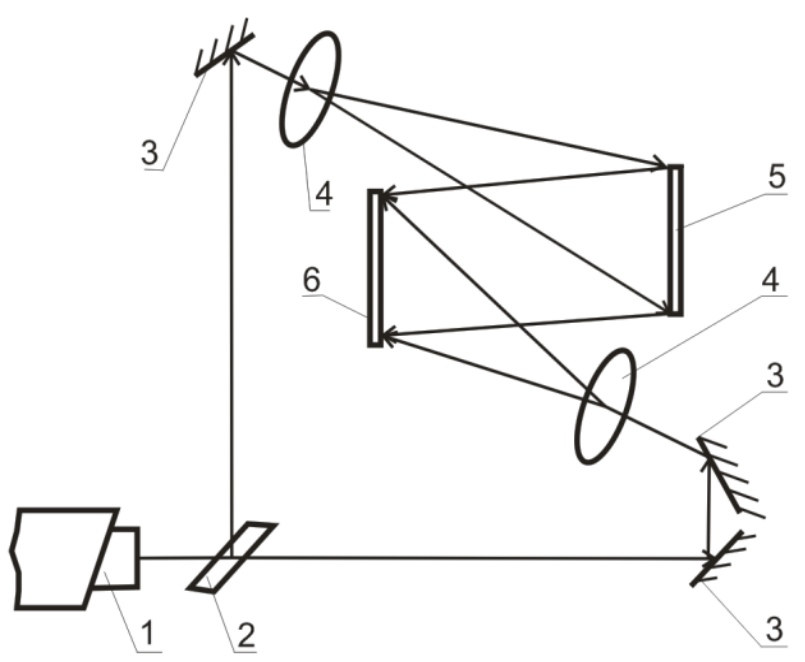

Fig. 3. A sketch of the holographic interferometry by double exposure method:

1 - laser ЛГ-38; 2 - divider; 3 - mirror; 4 - lens; 5 - the object; 6 - photographic plate

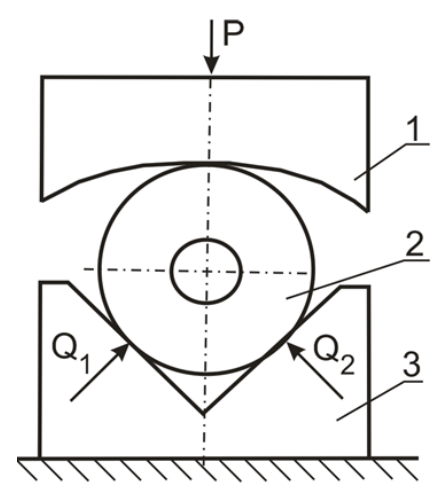

$a$

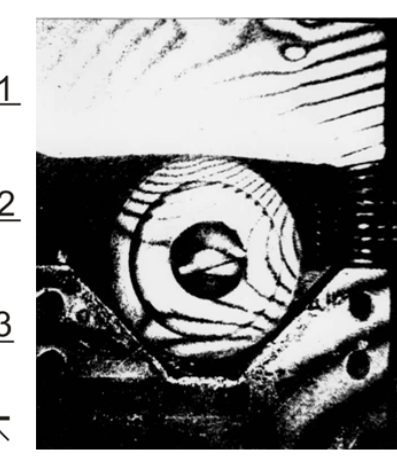

$b$
Fig. 4. The scheme $\mathrm{f}$ the load $(a)$ and the hologram of contact pair (b): 1,2 - fixed and movable contacts; 3 - supporting prism
Determination of deformation performed by records taking into account the position of the zero-order fringe and displacement vector directed perpendicular to the surface of contact. The difference in compliance sections of the contact surfaces is clearly seen by the number of interference fringes. The closer their net, the more displacement. In this clearly indicates the difference of the bands on the steel prism and on contact.

Calculation of movement of the contact surface reduces to a multiplication of the interference maximum sequence number the numerical value of the wavelength of the radiation source (in this case $0.3162 \mu \mathrm{m}$ ). Conditionally designating by serial numbers light strips on the image, offset is determined by the formula

$$
Z(x)=\frac{N \lambda}{2} \text {. }
$$

where $Z(x)$ is the displacement, $\mu \mathrm{m} ; N$ is the number of strips; $\lambda$ is the wave length, $\mu \mathrm{m}$.

Study of displacement of the contact surface is carried out in a static mode. During the experiment the force $P$ was changed stepwise in the range of variation of the force of compression contacts of the real device. There was a possibility to supply transformer oil to the contact zone that simulate the conditions of work of contacts in the oil-filled switchgear. Data obtained by using the following methods, are shown in Table. 2.

Table 2

Maximal displacements of the contact surfaces at various load conditions, $\mu \mathrm{m}$

\begin{tabular}{|c|c|c|c|c|}
\hline \multirow{2}{*}{ Material } & \multicolumn{3}{|c|}{ Load $P, \mathrm{~N}$} & \multirow{2}{*}{ HardnessHB } \\
\cline { 2 - 5 } M1 & 1300 & 2700 & 4000 & \\
\hline $\begin{array}{c}\text { KMK- } \\
\text { Б20 }\end{array}$ & $0.632 / 1.264 *$ & $1.264 / 3.160 *$ & $4.100 / 8.010 *$ & $100-110$ \\
\hline
\end{tabular}

* presence of transformer oil in the contact zone

According to the experimental results it can be seen that the comparison of the degree of deformation of the contact surfaces of the compact (cast) and powder materials in terms of their hardness is not quite correct, since deformation of the contact surface is greatly affected by homogeneity of the structure and porosity of the powder materials.

This method may determine the limit load for contact material without resorting to their destruction, as well as to predict the behavior of contacts for long term use.

\section{Conclusions.}

1. By the method of holographic interferometry it is possible to investigate the interaction of surfaces of breaking contacts of high-switching devices. The experimental results provide a more accurate picture of 
the deformation of the contact surface, taking into account a variety of factors that can not be taken into account in the simulation.

2. The influence on the deformation of the contact surfaces of the external environment in the oil-filled switchgear that at high loads of more than twice the increases displacement of the contact surface without visible damage under compression is demonstrated.

3. The use of the experimental method of determining the movement of the region near contacts allows to optimize operation of breaking contacts from composite and powder materials. For example, it was found that for the contactor of the on-load tap-changing transformer PHTA 35/320 the compressive force shall not exceed $4,060 \mathrm{~N}$, and the maximum deformation of the contact surface values of $8-11 \mu \mathrm{m}$.

\section{REFERENCES}

1. Taev I.S. Elektricheskie apparaty upravleniia [Electrical control apparatus]. Moscow, Vysshaia shkola Publ., 1984. 243 p. (Rus).

2. Butkevich G.V. Osnovy teorii elektricheskikh apparatov [Basic theory of electrical apparatus]. Moscow, Vysshaia shkola Publ., 1970. 600 p. (Rus).
3. Basov K.A. ANSYS v primerakh $i$ zadachakh [ANSYS in examples and tasks]. Moscow, Komp'iuter Press Publ., 2002. 224 p. (Rus).

4. Merl V. Elektricheskii kontakt. Teoriia i primenenie na praktike [Electrical contact. Theory and practical application]. Moscow-Leningrad, Gosenergoizdat Publ., 1962. 82 p. (Rus).

5. Myshkin N.K. Elektricheskie kontakty [Electrical contacts]. Dolgoprudnyi, Intellekt Publ., 2008. 560 p. (Rus).

6. Kashcheev V.N. Protsessy treniia v zone friktsionnogo kontakta metallov [Friction process in metal contact frictional zone]. Moscow, Mashinostroenie Publ., 1978. 211 p. (Rus).

7. Ginzburg V.M., Stepanova B.M. Golografiia. Metodyiapparatura [Holography. Methods and equipments]. Moscow, Sovetskoe radio Publ., 1974. 376 p. (Rus).

Received 22.10.2015

O.G. Volkova ${ }^{1}$, Candidate of Technical Science, Associate

Professor,

L.B. Zhornyak ${ }^{1}$, Candidate of Technical Science, Associate

Professor,

${ }^{1}$ Zaporozhye National Technical University,

64, Zhukovsky Str., Zaporozhye, 69063, Ukraine.

phone +3806127698304, e-mail: volkova@zntu.edu.ua

How to cite this article:

Volkova O.G., Zhornyak L.B. Investigation of high-current interrupting contacts working surfaces mechanical interaction nature. Electrical engineering \& electromechanics, 2016, no.1, pp. 12-16. doi: 10.20998/2074272X.2016.1.02. 